\title{
Studies on Paralytic Shellfish Poison (PSP) Toxification of Bivalves, in Association with Appearance of Alexandrium tamarense, in Hiroshima Bay, Hiroshima Prefecture
}

\author{
(Received October 9, 1992)
}

\author{
Manabu Asakawa ${ }^{* 1}$, Keisuke Miyazawa ${ }^{* 1}$ and Tamao Noguchi ${ }^{* 2}$ \\ ${ }^{* 1}$ Faculty of Applied Biological Science, Hiroshima University: 1-4-4, Kagamiyama, \\ Higashi-Hiroshima, Hiroshima 724, Japan; ${ }^{* 2}$ Laboratory of Marine Biochemistry, \\ Faculty of Agriculture, University of Tokyo: 1-1-1, \\ Yayoi, Bunkyo-ku, Tokyo 113, Japan)
}

\begin{abstract}
In April, 1992, paralytic toxicity substantially exceeding the quarantine limit of $4 \mathrm{MU} / \mathrm{g}$ edible part as paralytic shellfish poison (PSP) was detected in cultured oyster Crassostrea gigas, mussel Mytilus edulis and short-necked clam Tapes (Amygdala) japonica from Hiroshima Bay, Hiroshima Prefecture concomitantly with the appearance of the toxic dinoflagellate Alexandrium tamarense. The toxicities were $31.4 \mathrm{MU} / \mathrm{g}$ for oyster, $214.6 \mathrm{MU} / \mathrm{g}$ for mussel and 20.3 $\mathrm{MU} / \mathrm{g}$ for short-necked clam on 22 nd April.

Attempts were made to identify the paralytic toxin in these bivalves. They were extracted with $80 \%$ ethanol ( $\mathrm{pH} 3.5$ ), followed by defatting with dichloromethane. The aqueous layer obtained was ultrafiltered through a Diaflo YM-2 membrane (Amicon) to eliminate substances of more than 1,000 daltons, treated with activated charcoal and then applied to a Sep-Pak $\mathrm{C}_{18}$ cartridge (Waters). The unbound toxic fraction was analyzed by HPLC. In gonyautoxin (GTX) analysis of each toxin, protogonyautoxin- $1,2\left(\mathrm{PX}_{1,2} ;\right.$ epi-GTX $\left.8, \mathrm{GTX}_{8} ; \mathrm{C}_{1,2}\right), \mathrm{GTX}_{4}, \mathrm{GTX}_{1}, \mathrm{GTX}_{3}$ and $\mathrm{GTX}_{2}$ were detected. In saxitoxin (STX) analysis, a small peak of STX was detected in mussel and short-necked clam toxin, but not in the oyster toxin. Consequently, the toxin of the bivalves in Hiroshima Bay was found to be comprised of $\mathrm{GTX}_{1 \sim 4}$ as the major components, which accounted for approximately $92 \sim 95 \%$ (mole ratio) of all components, with a trace of STX. In all cases, $\mathrm{GTX}_{1}$ was the major component (approximately $51 \sim 55 \%$; mole ratio). On the other hand, the content of $\mathrm{PX}_{1,2}$, which are $N$-sulfocarbamoyl derivatives, was $1.6 \sim 4.5 \%$ (mole ratio) irrespective of the sample.

It was concluded from these results that the toxin of the above bivalves collected in Hiroshima Bay in April, 1992 consisted predominantly of PSP, possibly derived from the toxic plankton A. tamarense detected there.
\end{abstract}

Key words: paralytic shellfish poison; Alexandrium tamarense; oyster (Crassostrea gigas); mussel (Mytilus edulis); short-necked clam (Tapes (Amygdala) japonica); gonyautoxin; saxitoxin

\section{Introduction}

Oyster, Crassostrea gigas, is one of the most important edible bivalves, and is cultivated in several areas including Hiroshima Bay, where cultivation has been performed on a large scale for a long time.

In April, 1992, paralytic toxicity substantially exceeding the quarantine limit of $4 \mathrm{MU} / \mathrm{g}$ edible part as paralytic shellfish poison (PSP) was detected in oyster, mussel Mytilus edulis and short- necked clam Tapes (Amygdala) japonica from the same bay, concomitantly with the appearance of the toxic dinoflagellate Alexandrium tamarense ${ }^{1)}$, resulting in prohibition of their harvesting and marketing by the Hiroshima Prefectural Government. Since the occurrence of PSP in these bivalves was anticipated on the suspicion of toxification by $A$. tamarense, the toxin was characterized according to the procedure described below. PSP is one of the most notorious marine toxins. PSP, once ingested by humans, 
evokes mainly paralysis in part of the body, with death in severe cases ${ }^{2)}$. In connection with the present PSP toxification of bivalves in $\mathrm{Hi}$ roshima Bay, there were no food poisonings, fortunately. Since cultured oysters produced in Hiroshima Bay are shipped to many areas in Japan not only as fresh oysters but also as a raw material of processed foods such as smoked oyster and oyster sauce etc., toxification of oysters posed very serious problems to fishermen and other workers in associated industries as well as to public health.

There has been no previous record of PSP toxification of bivalves in Hiroshima Bay. These considerations prompted us to undertake identification of the paralytic toxins contained in oyster, mussel and short-necked clam from Hiroshima Bay in April, 1992.

\section{Materials and Methods}

\section{Materials}

Specimens of oyster Crassostrea gigas in a floating culture raft and mussel Mytilus edulis adhering to the same raft in Hiroshima Bay were collected on April 22, 1992. At the same time, specimens of short-necked clam Tapes (Amygdala) japonica were collected in the estuary of Ohta River, which faces the bay of Hiroshima City. They were transported to our laboratory on ice, and immediately used for purification of toxins as described below, as well as for toxicity examination.

\section{Assay of toxicity}

Toxicity was examined by means of the mouse assay method for PSP, using male mice of the ddY strain weighing 18 to $20 \mathrm{~g}^{3}$.

\section{Purification of toxins}

The toxins were partially purified from toxic specimens of oyster, mussel and short-necked clam, essentially according to the procedure previously reported ${ }^{4)}$ with several modifications as follows. Three volumes of $80 \%$ ethanol ( $\mathrm{pH} 3.5)$ were added to about $100 \mathrm{~g}$ of shucked meat of each bivalve and homogenized. The homogenate was centrifuged at 5,000 rpm for $15 \mathrm{~min}$. This operation was repeated twice more for the residue. The supernatants obtained were combined, concentrated under reduced pressure, and defatted with dichloromethane. The aqueous layer obtained was concentrated under reduced pressure, and ultrafiltered through a Diaflo YM2 membrane (Amicon) to eliminate substances of more than 1,000 daltons. The filtrate was adjusted to $\mathrm{pH} 5.5$ with hydrochloric acid, and then loaded onto a water-washed activated charcoal column $(2.5 \times 30 \mathrm{~cm})$, followed by washing with water. The toxic fraction was eluted with $1 \%$ acetic acid-20\% ethanol and then concentrated to dryness under reduced pressure. The toxin thus purified was dissolved in a small amount of water and chromatographed on a Sep-Pak $\mathrm{C}_{18}$ cartridge (Waters) column. The unbound fraction was toxic. The toxin obtained was analyzed by the HPLC method described below. At the same time, acid hydrolysis of the toxin obtained was performed with dilute hydrochloric acid for $15 \mathrm{~min}$ in boiling water. The hydrolyzate was also submitted to the same HPLC analysis.

\section{Identification of toxins}

The toxin composition was examined by the HPLC method using a reversed-phase YMC-gel ODS-5 (AM-314) column ${ }^{4}$. Briefly, the column was developed with $1 \%$ methanol- $0.05 \mathrm{M}$ potassium phosphate buffer ( $\mathrm{pH} 7.0$ ) for the gonyautoxin (GTX) group and 25\% methanol-0.05 M potassium phosphate buffer $(\mathrm{pH} 7.0)$ for the saxitoxin (STX) group, using $2 \mathrm{~m} M$ 1-heptanesulfonic acid sodium salt as an ion-pairing reagent. The toxins separated were finally detected by fluorescence measurement, following oxidation by periodate reagent. The reference standards of PSP used in this study were prepared as follows. GTX $_{1 \sim 4}$ were prepared from digestive glands of PSP-infested scallop Patinopecten yessoensis in Ofunato Bay, Iwate Prefecture by essentially the method of Noguchi et al. .) $^{5}$ NeoSTX and STX were prepared from exoskeleton of a xanthid crab Zosimus aeneus collected at Kabira in Ishigaki Island, Okinawa Prefecture, by the method of Daigo et al. ${ }^{6)}$

\section{Results and Discussion}

The oyster, mussel and short-necked clam collected from Hiroshima Bay on April 22, 1992 showed high toxicity scores of $31.4,214.6$ and $20.3 \mathrm{MU} / \mathrm{g}$, respectively, substantially exceed- 


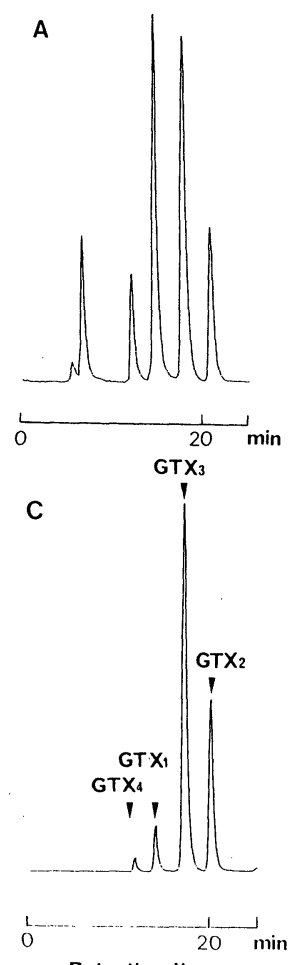

Retention time

Fig. 1. HPLC analysis of GTX group toxins contained in oyster from Hiroshima Bay

A: oyster toxin; B: acid hydrolyzate of oyster toxin; C: $\mathrm{GTX}_{4,1,3,2}$ standards

ing the quarantine limit of $4 \mathrm{MU} / \mathrm{g}$ edible part, and the signs manifested in mice were characteristic of PSP. In May, a decline of the toxicity level of bivalves to below quarantine limit resulted in removal of the quarantine.

HPLC profiles of the partially purified toxins from oyster, mussel and short-necked clam are shown in Figs. 1-4. The toxin patterns were very similar to each other. In GTX analysis, each toxin was composed mainly of five peaks, of which four were identified as $\mathrm{GTX}_{4}, \mathrm{GTX}_{1}$, $\mathrm{GTX}_{3}$ and $\mathrm{GTX}_{2}$ and the other near the void volume was regarded as protogonyautoxin (PX). On acid hydrolysis, the peak near the void volume, which was suspected to be PX, disappeared and instead the peaks of $\mathrm{GTX}_{2,3}$ increased, indicating that this peak with a retention time of about $6.6 \mathrm{~min}$ was comprised of $\mathrm{PX}_{1,2}$. STX analysis for mussel and shortnecked clam toxin showed a small peak of STX, but none was detected in the oyster toxin.

Hence, it can reasonably be concluded from
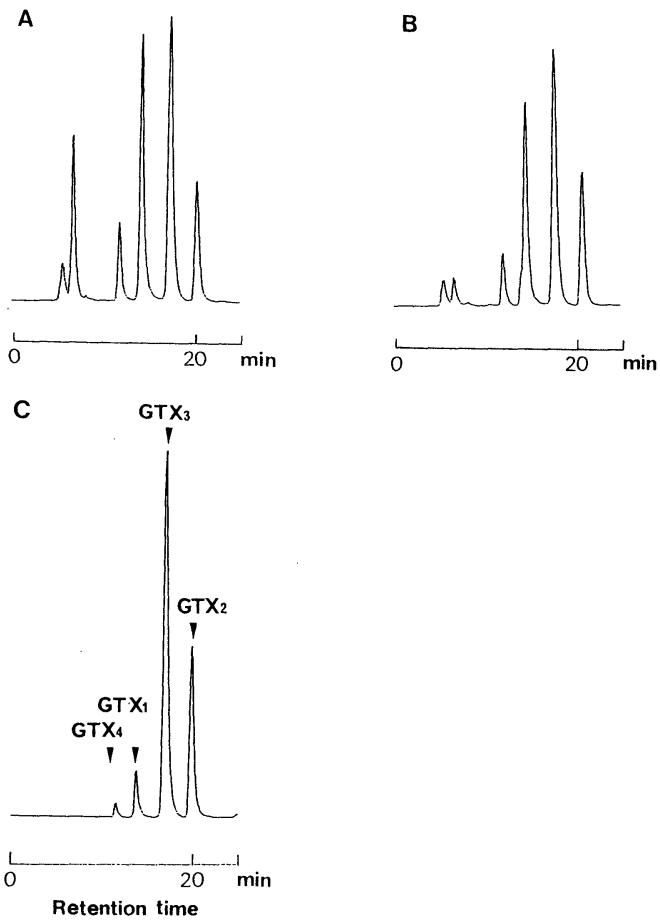

Fig. 2. HPLC analysis of GTX group toxins contained in mussel from Hiroshima Bay

A: mussel toxin; B: acid hydrolyzate of mussel toxin; C: $\mathrm{GTX}_{4,1,3,2}$ standards

the signs in the mouse assay and the results of HPLC analysis that the paralytic toxins of the above bivalves collected from Hiroshima Bay in April, 1992 were PSP. To our knowledge, this is the first report of PSP toxification of bivalves in Hiroshima Bay.

The toxin compositions of oyster, mussel and short-necked clam are shown in Fig. 5. The toxin of PSP-containing bivalves in Hiroshima Bay was found to consist predominantly of GTX $_{1 \sim 4}$, which accounted for about $92 \sim 95 \%$ of all components, along with trace amounts of STX. Above all, $\mathrm{GTX}_{1}$ was the major component (approximately 51 55\%; mole ratio) in all cases. On the other hand, the content of $\mathrm{PX}_{1,2}$, which are $N$-sulfocarbamoyl derivatives, was 1.6 $\sim 4.5 \%$ (mole ratio) irrespective of the sample.

In Japan, an outbreak of PSP toxification of oyster $C$. gigas by $A$. catenella followed by a food poisoning incident was reported in Senzaki Bay, Yamaguchi Prefecture in $1979^{7}$. Senzaki oyster toxin was reported to contain $\mathrm{GTX}_{1 \sim 3}$ and $\mathrm{GTX}_{5}$, which is suspected to be a precursor of STX, as 


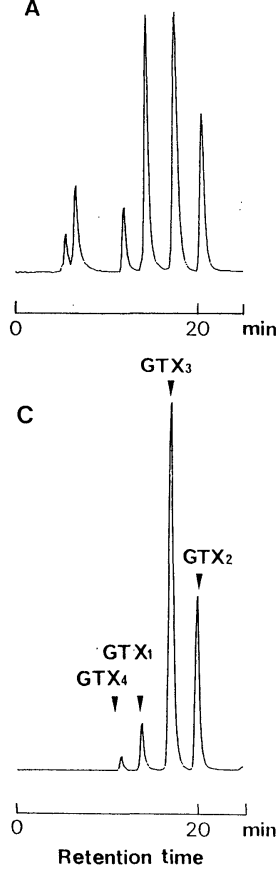

Fig. 3. HPLC analysis of GTX group toxins contained in short-necked clam from Hiroshima Bay

A: short-necked clam toxin; B: acid hydrolyzate of short-necked clam toxin; C: $\mathrm{GTX}_{4,1,3,2}$ standards
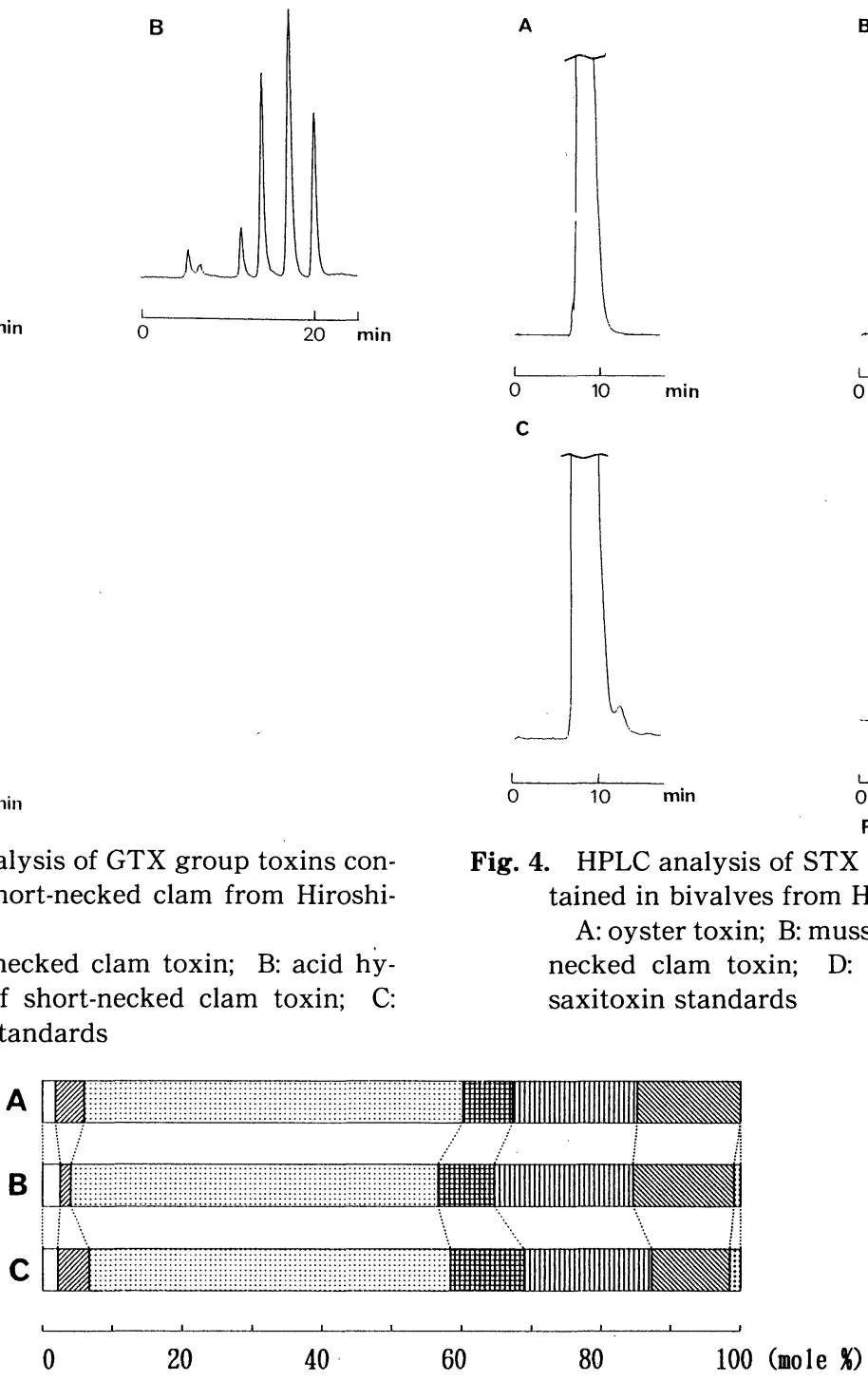

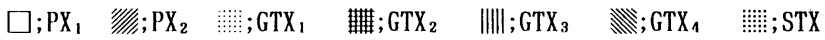

Fig. 5. Toxin composition of bivalves from Hiroshima Bay in April, 1992 A: oyster; B: mussel; C: short-necked clam
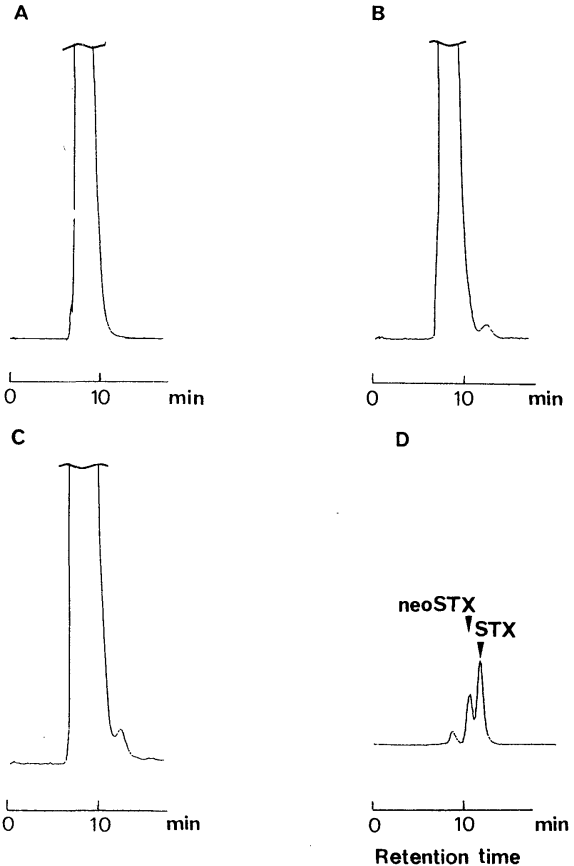

Fig. 4. HPLC analysis of STX group toxins contained in bivalves from Hiroshima Bay

A: oyster toxin; B: mussel toxin; C: shortnecked clam toxin; D: neosaxitoxin and saxitoxin standards the major components, and STX group (neoSTX and STX) as minor components. Soon after, $\mathrm{PX}_{1,2}$ were newly separated from toxic oysters in Senzaki Bay and their chemical structures were characterized ${ }^{8)}$. In December 1986 , oyster in Senzaki Bay was toxified with a dinoflagellate Gymnodinium catenatum containing mainly $\operatorname{PX}_{1,2} \quad\left(\mathrm{C}_{1,2}\right)$ and $\operatorname{GTX}_{6}(61.3 \%, 36.0 \%$; mole ratio $)^{9}$.

The toxin of PSP-containing bivalves in Hi- roshima Bay was found to be comprised of GTX group $\left(\mathrm{PX}_{1,2}\right.$ and $\left.\mathrm{GTX}_{1 \sim 4}\right)$ as the major components, with a trace of STX. In Funka Bay, Hokkaido, A. tamarense is responsible for PSP toxification of cultured scallop $P$. yessoensis, which is one of the most important products of the fisheries industry of Hokkaido, from late spring to early summer. Its PSP composition varies somewhat depending upon season and year, but commonly includes the STX group as 
minor components (approximately 10 20\%; mole ratio $)^{10)}$. The PSP composition of oyster, mussel and short-necked clam in Hiroshima Bay is unusual in this respect.

In Japan, $A$. tamarense was first found in Ofunato Bay, Iwate Prefecture ${ }^{11)}$ as the plankton responsible for PSP toxification of bivalves, and was subsequently found in other areas such as Funka Bay and Seto Inland Sea. Unlike $A$. catenella, this species never forms a red tide, but often toxifies scallop and other bivalves in rather low density to an extremely high level. From Hokkaido to Kyushu, bivalves are often toxified with toxic dinoflagellates, depending upon locality, season and year. A total of twenty-seven PSP poisoning incidents have so far been recorded in Japan from 1979 to 1989 including two deaths ${ }^{12)}$. However, in Hiroshima Prefecture, there is no record of previous PSP toxification of bivalves followed by food poisonings. From both an economic and a foodhygienic point of view, it is a very important problem. Judging from the history of other areas where PSP toxification has occurred, PSP toxification of bivalves may occur repeatedly in Hiroshima Bay from now on. Therefore, surveillance for toxic bivalves and dinoflagellates such as A. tamarense, A. catenella and G. catenatum throughout the year is urgently needed. Moreover, it is necessary to consider sediment, bottom soil and fouling organisms ${ }^{10,13)}$ as possible causative factors of PSP toxification of bivalves, in addition to PSP-producing dinoflagellates.

\section{References}

1) Hashimoto, K., Noguchi, T.: Pure \& Appl. Chem. 61, 7 18 (1989).

2) Noguchi, T., Asakawa, M., Hashimoto, K.: Jpn. J. Toxicol. 2, 145 152 (1989).

3) Environmental Health Bureau, Ministry of Health and Welfare, ed.: "Food Hygiene Examination Manual" Vol. 2 p. 232 244 (1978), Japan Food Hygiene Association, Tokyo.

4) Noguchi, T., Asakawa, M., Arakawa, O., Fukuyo, Y., Nishio, S., Tanno, K., Hashimoto, K.: "Toxic Marine Phytoplankton" p. 493 498 (1990), Elsevier, New York.

5) Noguchi, T., Kono, M., Ueda, Y., Hashimoto, K.: J. Chem. Soc. Japan 5, 652 658 (1981).

6) Daigo, K., Uzu, A., Arakawa, O., Noguchi, T., Seto, H., Hashimoto, K.: Nippon Suisan Gakkaishi 51, 309 313 (1985).

7) Onoue, Y., Noguchi, T., Hashimoto, K.: ibid. 46, 1,031 1,034 (1980).

8) Onoue, Y., Noguchi, T., Maruyama, J., Hashimoto, K., Seto, H.: J. Agric. Food Chem. 31, 420 423 (1983).

9) Oshima, Y., Sugino, K., Itakura, H., Hirota, M., Yasumoto, T.: "Toxic Marine Phytoplankton" p. 391 396 (1990), Elsevier, New York.

10) Noguchi, T., Asakawa, M., Tanno, K., Takayama, M., Hashimoto, K.: submitted to Marine Biology.

11) Ueda, Y., Noguchi, T., Onoue, Y., Koyama, K., Kono, M., Hashimoto, K.: Nippon Suisan Gakkaishi 48, 455 458 (1982).

12) Noguchi, T.: Food Sanitation Research 42, 23 41 (1992).

13) Noguchi, T., Asakawa, M., Hashimoto, K.: "Emerging Food Safety Problem Resulting from Microbial Contamination" p. 93 102 (1992), Kohken Press, Tokyo. 